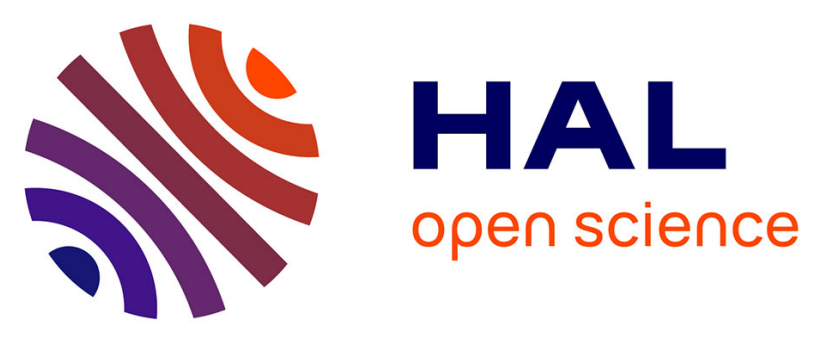

\title{
Randomised clinical trials: Early assessment after two weeks of high-dose mesalazine for moderately active ulcerative colitis - new light on a familiar question
}

Timothy Orchard, Stefan van Der Geest, Simon P L Travis

\section{- To cite this version:}

Timothy Orchard, Stefan van Der Geest, Simon P L Travis. Randomised clinical trials: Early assessment after two weeks of high-dose mesalazine for moderately active ulcerative colitis - new light on a familiar question. Alimentary Pharmacology and Therapeutics, 2011, 33 (9), pp.1028. 10.1111/j.13652036.2011.04620.x . hal-00620577

\section{HAL Id: hal-00620577 \\ https://hal.science/hal-00620577}

Submitted on 8 Sep 2011

HAL is a multi-disciplinary open access archive for the deposit and dissemination of scientific research documents, whether they are published or not. The documents may come from teaching and research institutions in France or abroad, or from public or private research centers.
L'archive ouverte pluridisciplinaire HAL, est destinée au dépôt et à la diffusion de documents scientifiques de niveau recherche, publiés ou non, émanant des établissements d'enseignement et de recherche français ou étrangers, des laboratoires publics ou privés. 


\begin{tabular}{l}
\hline Alimentary Pharmacology \\
\hline \& Therapeutics \\
\hline
\end{tabular}

\section{Randomised clinical trials: Early assessment after two weeks of high-dose mesalazine for moderately active ulcerative colitis - new light on a familiar question}

\begin{tabular}{|r|l|}
\hline Journal: & Alimentary Pharmacology \& Therapeutics \\
\hline Manuscript ID: & APT-0026-2011.R1 \\
\hline Wiley - Manuscript type: & SuperFast \\
\hline $\begin{array}{r}\text { Date Submitted by the } \\
\text { Author: }\end{array}$ & 09-Feb-2011 \\
\hline Complete List of Authors: & $\begin{array}{l}\text { Orchard, Timothy; St Mary's Hospital, GI Unit } \\
\text { Van Der Geest, Stefan; Warner Chilcott UK Ltd } \\
\text { Travis, Simon; John Radcliffe Hospital, Gastroenterology }\end{array}$ \\
\hline Keywords: & $\begin{array}{l}\text { Inflammatory bowel disease < Disease-based, Ulcerative colitis < } \\
\text { Disease-based, X keyword = no topic , Y keyword = no topic }\end{array}$ \\
\hline \multicolumn{2}{|c}{} \\
\hline
\end{tabular}




\title{
Early assessment after 2 weeks of high dose 5-ASA for moderately active UC: new light on a familiar question Response to comments
}

\begin{abstract}
Editor
Can you assure me that you can provide written permission from the Authors of the two studies that provided the data, and that this is the only post-hoc analysis of these data that is being published?

The two original ASCEND studies and the current analysis were all sponsored by Procter \& Gamble Pharmaceuticals/Warner Chilcott. As such, we are pleased to confirm that permission has been granted for the current analysis to be conducted and submitted for publication.

We are also pleased to confirm that the current analysis is the only post-hoc analysis of the patient diary data and the time to symptom improvement that has been performed. We acknowledge that other analyses of the ASCEND data have been presented (including a recent analysis of mucosal healing, Lichtenstein et al., Aliment Pharmacol Ther 2011), but the current study is the only analysis of the symptom data. As such, this manuscript presents a new and unique insight into symptom resolution with high-dose 5ASA therapy, and evaluates practical recommendations on the timescales for treatment review.
\end{abstract}

AP\&T has a specific style for some Titles, for example "Randomised clinical trial: ....", hence this Title should be, "Randomised clinical trials: early assessment after two weeks of high-dose mesalazine for moderately active ulcerative colitis".

The title of the manuscript has been amended accordingly:

"Randomised clinical trials: Early assessment after two weeks of high-dose mesalazine for moderately active ulcerative colitis - new light on a familiar question"

AP\&T has a specific style for the Summary: Background, Aim, Methods, Results, Conclusions - all in $<\mathbf{2 5 0}$ words. The Clinical trial number should be at the end of the Summary, and not within the word limit.

As requested, the clinical trial numbers for the ASCEND I and II studies has been added to the end of the Summary. Additional amends have been made to the Summary in line with the requested word limit.

"(Clinicaltrials.gov: NCT00577473, NCT00073021)" 


\section{Reviewer: 1 \\ Orchard et al present an analysis of data combined from ASCEND I and II. In these studies, patients with moderately active ulcerative colitis were randomised to $\mathbf{2 . 4 g / d a y ~ o r ~} 4.8 \mathrm{~g}$ / day of asacol. They show a more rapid improvement and resolution of rectal bleeding and the combined endpoint of rectal bleeding and stool frequency but no more rapid an improvement in stool frequency with $\mathbf{4 . 8 g}$.}

There are a number of problems with this paper.

1. It has all of the inherent weaknesses of industry sponsored studies particularly with relation to post-hoc analyses.

Some elements of this study are indeed based on post hoc analyses, although we note that the time to symptom resolution was a prespecified secondary endpoint of the ASCEND studies. We acknowledge that such post hoc analyses display certain limitations with regard to their interpretation. We have amended the Summary section to clearly state upfront that post hoc analyses were employed.

Summary, pg 3:

"A combination of pre-specified and post hoc analyses were used."

It is stated in the Materials and Methods section that the analysis of time to symptom resolution was prespecified, whereas the remainder of the analyses were post hoc.

Materials and Methods, pg 8-9:

"Time to symptom resolution was a prespecified secondary endpoint of ASCEND I and II...

"The time to symptom improvement and the proportion of patients achieving improvement or resolution of rectal bleeding and/or stool frequency at the clinically relevant time point of day 14 were evaluated in post hoc analyses."

The limitations of post hoc analysis are also briefly highlighted in the Discussion section.

Discussion, pg 17:

"There are some limitations in the current analyses, as with all post hoc analyses."

2. What role did the authors have in conception and design of the study? None of them are listed in the author list of the Marion et al abstract.

The authors confirm that they were involved in the conception and design of the analyses presented in this manuscript, although they were not involved in the conduct of the ASCEND I and II studies. Stefan van der Geest is an employee of Warner Chilcott Pharmaceuticals, and was involved in the conception and design of all analyses. Tim 
Orchard and Simon Travis played lead roles in proposing and designing the post hoc analyses of symptom scores at day 14 . All three authors contributed to the interpretation of the data and were involved in preparation of the manuscript.

\section{The oft quoted (in this paper) ECCO statement about assessing response of rectal bleeding at 10-14 days is not evidence based and appears to have been derived from the results of ASCEND II which leads to a circular logic - ASCEND II shows a median response with $4.8 \mathrm{~g}$ of asacol of 9 days compared to 16 days with $2.4 \mathrm{~g} / \mathrm{day}$ and a post hoc analysis of ASCEND I and II unsurprisingly supports this opinion.}

The advice from ECCO that treatment response may be assessed after 10-14 days is based on a consensus of several leading experts in the field of IBD. This is indeed partly influenced by initial findings from ASCEND II, but detailed evaluations of symptom resolution at day 14 were not available at that time. One of the aims of the present study was to evaluate this recommendation, by examining in detail the percentage of patients experiencing symptom improvement at a corresponding time point, based on a large patient population from both ASCEND I and II. This is not circular logic, but rather a more detailed and comprehensive analysis of the evidence. The findings of this analysis expand on the previous top-line analyses, and thereby provide evidence to support the practical clinical recommendation from ECCO.

\section{Patients were excluded from ASCEND I and II if taking 5-ASAs. This should be explicitly stated in this paper as one cannot necessarily generalise these results to those already on maintenance 5-ASAs.}

As the reviewer notes, the exclusion criteria of the ASCEND I and II studies (published previously ${ }^{1,2}$ ) included use of oral 5-aminosalicylate-containing products at a dose $>1.6 \mathrm{~g} /$ day or topical rectal therapies within the last 7 days. However, we note that lower doses were permitted. We acknowledge that this means the findings may not be directly applicable to those patients receiving maintenance 5-ASA therapy at a dosage above $1.6 \mathrm{~g} /$ day. A sentence has been added to the Discussion section accordingly.

Discussion, pg 17:

"For example, exclusion of patients receiving 5-ASA >1.6 g/day from the original studies means that it is unclear how applicable the current findings are to patients receiving higher maintenance doses of 5-ASA before treatment of the active disease."

Interestingly, in another prespecified subgroup analysis of the ASCEND data, it has been demonstrated that the effect of 5-ASA therapy is larger in patients who have previously taken 5-ASAs; detailed discussion of these data is beyond the scope of the current manuscript. 
5. There are several mentions of improvement or resolution in stool frequency. These improvements are not statistically significant and in some cases not clinically significant (1 day more rapid improvement in stool frequency and $2 \%$ more patients with improvement or resolution). They would be best referred to as being no difference between $2.4 \mathrm{~g}$ and $4.8 \mathrm{~g}$.

We acknowledge that the differences between doses with regard to stool frequency are not statistically significant, and agree that the presentation of the data may be confusing. We have adapted the text to clarify that the differences between the doses were not significant.

Results, pg 11:

"There was no significant difference between treatments in the median time to resolution of stool frequency (12 days vs 15 days for $4.8 \mathrm{~g} /$ day and $2.4 \mathrm{~g} /$ day, respectively; $p=0.206$; Figure 1A)."

Results, pg 13:

"No statistically significant differences were observed between doses in the number of patients experiencing improvement or resolution of stool frequency, with more than $80 \%$ of patients in both treatment groups experiencing symptom improvement (improvement, $p=0.375$; resolution, $p=0.329$; Figure 3)."

\section{The data presented in relation to 14 day findings is a little confusing (Symptom} outcomes after 6 weeks in relation to day 14 findings and table 3). $64 \%$ of patients in the $4.8 \mathrm{~g}$ group had resolution of bleeding at day 14 . However, only $67 \%$ of those who had experienced an improvement at day 14 had resolution of bleeding at 6 weeks. Did large numbers of patients deteriorate after day 14? Should the table read "No further improvement"?

We acknowledge that the information presented in this section is complex. In order to conduct the comparison of outcomes at day 14 and week 6 , it was necessary to include only patients for whom full data were available at both timepoints. Therefore, of the 143 patients who experienced improvement in rectal bleeding at day 14, 125 were included in the current analysis.

In addition, it should be noted that improvements in symptom score are defined relative to the baseline symptom score. Therefore, patients experiencing improvement at both day 14 and week 6 may have improved further after day 14, or may have remained the same. The definitions of improvement and resolution are such that any patients experiencing resolution of symptoms would also be classified as experiencing improvement, but patients not showing resolution may still be improved compared to baseline. 
Thus, out of 125 patients with improvement in rectal bleeding at day 14, 84 patients $(67 \%)$ experienced resolution at week 6 . A total of 108 patients $(86 \%)$ displayed improvement in rectal bleeding compared to baseline at week 6 . The remaining 17 patients (14\%) deteriorated to their baseline score or worse.

To clarify this issue, footnotes have been added to Table 3 and Table 4.

Table 3, pg 24:

"All improvements in symptom score are defined relative to the patient's baseline score. Patients showing improvement at day 14 but no improvement at week 6 experienced deterioration of symptoms to their baseline level or worse."

Table 4, pg 25:

"All improvements in symptom score are defined relative to the patient's baseline score."

7. What about those patients who had not improved at day 14? To justify this as a valid time for assessment of treatment success it is necessary to show that those who had not improved failed to develop resolution of symptoms. Otherwise one would simply continue with treatment rather than escalating to corticosteroids. Clearly more rapid improvement/ resolution is a worthy goal but there would need to be justification for escalation to corticosteroids with their attendant side effects.

We agree that it is important to consider the treatment outcomes for patients who did not show improvements at day 14, and are pleased to provide an additional analysis of these patients. A paragraph has been added to the Results section, and a sentence added to the Discussion section accordingly. Of patients who did not show improvements in rectal bleeding at day 14 , only about half went on to show improvements after 6 weeks. This indicates that only a minority of patients who do not improve by day 14 will show later improvements with prolonged treatment, confirming that day 14 is a valid point at which to consider treatment options.

Results, pg 14:

"To further assess the prognostic value of day 14, patients had not responded at day 14 were also considered (Table 4). Of those patients who did not show symptom improvement in rectal bleeding after 14 days, 54\% of these patients did not show improvement and 54\% did not show symptom resolution at week 6 (4.8 g/day group; Table 4). Similarly, for stool frequency, of those patients who did not experience improvement at day 14, 75\% did not show improvement and $85 \%$ did not show resolution at week 6 (4.8 g/day group; Table 4). Thus, failure to respond at 14 days predicted failure to respond at week 6 in the majority of patients."

Discussion, pg 15:

"Of patients who did not show improvement in rectal bleeding after 2 weeks, only about half went on to experience symptom resolution after 6 weeks." 
Reviewer: 2

This post hoc analysis of previously published studies clearly sets out its aims and methodology

The discussion is well written and is a helpful view of these data in the context of clincal practice and the ECCO consensus guidelines. It serves as a helpful review for practising clinicians in the use and limtations of higher doses of 5 ASA drugs as studied in AScend 1 and II

We gratefully acknowledge the reviewer's comments. No further amendments to the manuscript have been made.

\section{References}

(1) Hanauer SB, Sandborn WJ, Dallaire C, Archambault A, Yacyshyn B, Yeh C, et al. Delayed-release oral mesalamine $4.8 \mathrm{~g} /$ day (800 $\mathrm{mg}$ tablets) compared to 2.4 $\mathrm{g} /$ day (400 mg tablets) for the treatment of mildly to moderately active ulcerative colitis: The ASCEND I trial. Can J Gastroenterol 2007;21(12):827-34.

(2) Hanauer SB, Sandborn WJ, Kornbluth A, Katz S, Safdi M, Woogen S, et al. Delayed-release oral mesalamine at $4.8 \mathrm{~g} /$ day $(800 \mathrm{mg}$ tablet) for the treatment of moderately active ulcerative colitis: the ASCEND II trial. Am J Gastroenterol 2005;100(11):2478-85. 


\section{Randomised clinical trials: Early assessment after two weeks of} high-dose mesalazine for moderately active ulcerative colitis new light on a familiar question

\author{
Authors: T R Orchard, ${ }^{1}$ S A P van der Geest, ${ }^{2}$ S P L Travis ${ }^{3}$ \\ ${ }^{1}$ GI Unit, St Mary's Hospital, Imperial College Healthcare NHS Trust, London, UK \\ ${ }^{2}$ Warner Chilcott UK Ltd, Larne, UK \\ ${ }^{3}$ Translational Gastroenterology Unit, John Radcliffe Hospital, Oxford, UK
}

For submission to Aliment Pharmacol Ther

Short title: Time to symptom resolution with high-dose 5-ASA

\section{Corresponding author and submission guarantor: T R Orchard}

GI Unit, St Mary's Hospital, Imperial College Healthcare NHS Trust,

Praed Street,

LONDON W2 1NY

UK

Tel: 02078861072

Fax: 02078866871

t.orchard@imperial.ac.uk
Deleted: 2

Deleted:

Deleted: 5-ASA

Deleted: UC

Deleted: : 


\section{Key words}

- 5-aminosalicylic acid (5-ASA)

- Mesalazine

- High-dose

\section{Previous presentation of data}

Median time to symptom resolution

Marion JF, Safdi M, Schwartz DA et al. Comparison of time to symptom resolution with oral mesalamine $4.8 \mathrm{~g} /$ day ( $800 \mathrm{mg}$ tablet) versus $2.4 \mathrm{~g} / \mathrm{day}$ (400 mg tablet): analysis of data from two randomized, double-blind, clinical trials in patients with moderately active ulcerative colitis. Am J Gastroenterol 2006;100(s9):s290, Abstract 783.

Symptom resolution and improvement at day 14

Orchard TR, Ramsey D, Geest SAPvd, Travis S. Reducing the time to symptom improvement and resolution for moderately active UC. J Crohn's Colitis 2009;3:S48, Abstract P095. 


\section{SUMMARY}

Background

Rapid resolution of rectal bleeding (RB) and stool frequency (SF) is an important goal for ulcerative colitis (UC) therapy and may help guide therapeutic decisions.

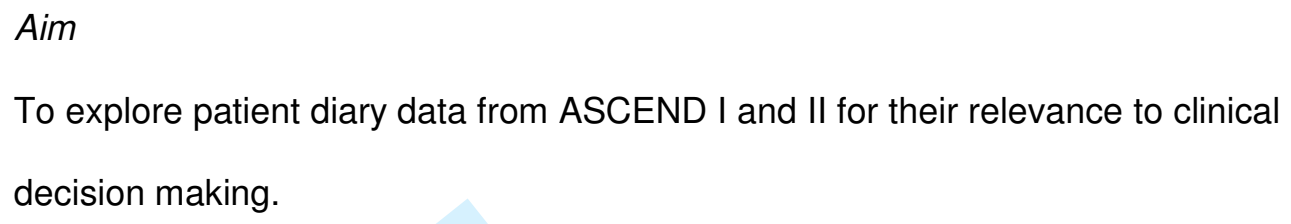


$p=0.035)$. Symptom relief after 14 days was associated with a high rate of symptom relief after 6 weeks.

\section{Conclusions}

High-dose mesalazine $4.8 \mathrm{~g} /$ day provides rapid relief of the cardinal symptoms of moderately active UC. Symptom relief within 14 days was associated with symptom relief at 6 weeks in the majority of patients. Day 14 is a practical timepoint at which response to treatment may be assessed and decisions regarding therapy escalation made.

(Clinicaltrials.gov: NCT00577473, NCT00073021) 


\section{INTRODUCTION}

The speed of response to treatment of active ulcerative colitis (UC) matters to patients. ${ }^{1}$ The cardinal symptoms of active UC are rectal bleeding, stool frequency, urgency and abdominal pain, ${ }^{2-4}$ and these symptoms have substantial detrimental effects on the quality of life of sufferers. ${ }^{3,5}$ Moreover, patients typically experience such symptoms for a considerable number of days per year: nearly $40 \%$ of patients experience symptoms for more than 180 days per year and twothirds of patients experience relapses every few months.,

In clinical trials, emphasis is usually placed on treatment response after a fixed period, as assessed using a variety of rating scales for disease activity, such as the UC disease activity index (UC-DAI). ${ }^{7,8}$ Although such scales are useful for providing detailed comparisons and the statistical power necessary for clinical trials, ${ }^{8}$ improvement in symptoms is very important from the point of view of both patients and physicians. Indeed, in a survey conducted by the European Federation of Crohn's and Colitis Associations (EFCCA), both gastroenterologists and UC patients identified fast symptom relief as one of six key treatment goals for UC therapy. ${ }^{1}$

Treatment guidelines from the British Society of Gastroenterology (BSG) and the American College of Gastroenterology (ACG), and an evidence-based consensus from the European Crohn's and Colitis Organisation (ECCO) all recommend 5-aminosalicylates (5-ASAs), such as mesalazine, as effective firstline therapies for mildly and moderately active UC. ${ }^{9-11}$ When selecting therapy, 
physicians should consider a number of factors, including the severity, extent and natural history of the disease, ${ }^{2,11}$ but the speed of symptom relief should also form an important part of therapeutic decisions.

Treatment recommendations from ECCO advise that in patients who do not respond within 10-14 days, escalation of therapy should be considered. ${ }^{11}$ However, to date, treatment response after 14 days has rarely been reported in clinical trials.

To test this recommendation, symptom relief (improvement and resolution) was evaluated by analyzing a series of large clinical trials of mesalazine for the treatment of active UC, based on data collected from patients' daily diaries. In the ASCEND I and II studies (Assessing the Safety and Clinical Efficacy of a New Dose of 5-ASA [4.8 g/day, $800 \mathrm{mg}$ tablet]), a high dose of mesalazine, $4.8 \mathrm{~g} / \mathrm{day}$ (Asacol $^{\circledR} 800$ mg MR tablet [UK and Canada], Asacol ${ }^{\circledR}$ HD [US], Warner Chilcott Ltd, Larne, UK), was compared to mesalazine $2.4 \mathrm{~g} /$ day $\left(\right.$ Asacol ${ }^{\circledR} 400 \mathrm{mg}$ delayed release tablet [US], Warner Chilcott Ltd, Larne, UK), over 6 weeks of treatment. The third study in this series, ASCEND III, differed in methodology from the previous studies because it did not include patient diaries in its protocol; therefore only data from ASCEND I and II are included in the current analysis.

In this paper, we report results relating to the prespecified analyses of time to improvement and resolution of the hallmark symptoms of UC (rectal bleeding and increased stool frequency) with high-dose mesalazine ( $4.8 \mathrm{~g} /$ day) compared to 
mesalazine $2.4 \mathrm{~g} /$ day. We also report a post hoc evaluation of the proportion of patients who experienced symptom improvement or resolution by the clinically meaningful time point of day 14. Finally, we report an assessment of the clinical symptoms after 6 weeks of treatment in comparison to the corresponding symptoms after 14 days, and discuss the relevance of these results for clinical practice and therapeutic decision-making in UC. 


\begin{abstract}
MATERIALS AND METHODS
Study design and participants

Data from two multi-centre, Phase III, randomized, double-blind, double-dummy, active-controlled studies of 6 weeks duration (the ASCEND I and II trials ${ }^{12,13}$ ) were combined and analysed. Study design and methodology of both ASCEND I and II trials have been reported in detail. ${ }^{12,13}$
\end{abstract}

Eligible patients were randomized in a 1:1 ratio to receive oral mesalazine $2.4 \mathrm{~g} /$ day (400 $\mathrm{mg}$ tablet) or oral mesalazine $4.8 \mathrm{~g} /$ day (800 $\mathrm{mg}$ tablet). All patients also received one of two placebo treatments, to maintain a doubledummy design. Both patients and investigators were blinded to treatment assignment. Although not prespecified in the protocols, the trials were designed so that data from the individual trials could be combined into one data set following completion of both studies.

Efficacy assessments and post hoc analyses

Evaluations of efficacy were performed in the intent-to-treat (ITT) population, defined as all randomized patients who received at least one dose of study medication and had a known treatment outcome at week 6 . Time to symptom resolution was a prespecified secondary endpoint of ASCEND I and II, and comprised two elements: a) normalization of stool frequency and b) resolution of rectal bleeding. Patients recorded data regarding rectal bleeding and stool frequency symptoms using daily diaries. Patient diary data were collected 
through daily telephone calls to an interactive voice response system (IVRS), from which the time to symptom resolution was calculated.

Analyses of the time to symptom resolution were based on the number of days between the first day of study medication and the first day of symptom resolution, determined from patient diary data. Symptoms were scored using a four-point scale (Table 1). Resolution of rectal bleeding was defined as a rectal bleeding symptom score of 0 (no visible blood in stool). Similarly, resolution of stool frequency was defined as a symptom score of 0 (normal stool frequency). The median time to symptom resolution was calculated as the time at which $50 \%$ of patients achieved symptom resolution. Improvement in rectal bleeding and stool frequency were defined as a decrease of at least one point from baseline in the respective symptom score.

The time to symptom improvement and the proportion of patients achieving improvement or resolution of rectal bleeding and/or stool frequency at the clinically relevant time point of day 14 were evaluated in post-hoc analyses. Additional analyses investigated the appropriateness of day 14 for assessing the response to 5-ASA therapy, by evaluating patients' symptom improvement or resolution after 6 weeks in comparison to their corresponding symptom scores at day 14 . 


\author{
Statistical analysis \\ Statistical analyses and sample size calculations in the ASCEND I and II studies \\ have been reported previously. ${ }^{12,13}$ In the current analyses, times to symptom \\ improvement and resolution were evaluated using survival analysis methods and \\ Kaplan-Meier estimates. Kaplan-Meier estimates are provided for each \\ treatment group. Log-rank tests were used to evaluate differences between the \\ $2.4 \mathrm{~g} /$ day and $4.8 \mathrm{~g} /$ day doses. Patients with a known treatment outcome at \\ week 6 who withdrew from the study prior to completion were censored at the \\ time of withdrawal. Patients who did not achieve symptom improvement or \\ resolution at the end of the 6-week study period were also censored.
}




\begin{abstract}
RESULTS
Patient characteristics

A total of 687 patients with mild to moderately active UC were randomized to treatment in the two studies. Of these patients, 448 had moderately active disease. In total, 423 patients with moderately active UC were included in the overall efficacy ITT population, comprising 200 patients in the $4.8 \mathrm{~g}$ /day group and 223 patients in the $2.4 \mathrm{~g}$ /day group. Symptom score data were available for the majority of patients in the ITT population. Baseline demographic and disease characteristics were similar between treatment groups (Table 2).
\end{abstract}

\author{
Median time to symptom resolution and improvement \\ Median times to resolution and improvement of rectal bleeding and stool \\ frequency symptoms are shown in Figure 1. Resolution of rectal bleeding was \\ achieved in a shorter median time with mesalazine $4.8 \mathrm{~g} /$ day, compared to \\ mesalazine $2.4 \mathrm{~g} /$ day (9 days vs 16 days, respectively; $p=0.007$; Figure $1 \mathrm{~A}$ ). \\ There was no significant difference between treatments in the median time to \\ resolution of stool frequency (12 days vs 15 days for $4.8 \mathrm{~g} /$ day and $2.4 \mathrm{~g} /$ day, \\ respectively; $p=0.206$; Figure $1 A$ ). When rectal bleeding and stool frequency \\ were evaluated together (i.e. both resolution of rectal bleeding and normalization \\ of stool frequency), the median time to symptom resolution was significantly \\ shorter with the $4.8 \mathrm{~g} /$ day dose, compared to the $2.4 \mathrm{~g} /$ day dose (19 days and \\ 29 days, respectively; $p=0.020$; Figure $1 \mathrm{~A}$ ).
}


Similar results were observed for symptom improvement. The median time to improvement in both rectal bleeding and stool frequency combined was shorter with $4.8 \mathrm{~g} /$ day than $2.4 \mathrm{~g} /$ day ( 7 days vs 9 days, respectively; $p=0.024$; Figure 1B). The individual symptoms of rectal bleeding and stool frequency both improved in median times of 4 and 5 days with mesalazine $4.8 \mathrm{~g} /$ day and $2.4 \mathrm{~g} /$ day, respectively $(p=0.027$ and $p=0.348$ for rectal bleeding and stool frequency, respectively; Figure 1B).

\section{Symptom improvement and resolution over time \\ Survival analyses for improvement or resolution of both rectal bleeding and stool frequency combined are shown in Figure 2. Treatment with mesalazine $4.8 \mathrm{~g} / \mathrm{day}$ was associated with consistently higher rates of both symptom improvement and complete resolution of symptoms, compared to mesalazine $2.4 \mathrm{~g} /$ day. Visual separation of the curves was observed within 1 week of treatment initiation, and was maintained throughout the study (Figure 2).}

\section{Symptom improvement and resolution at day 14}

A post hoc analysis of symptom improvement and resolution at day 14 was conducted, based on the survival analysis. At this time point, more patients had experienced improvement or resolution of symptoms with $4.8 \mathrm{~g} /$ day, compared to $2.4 \mathrm{~g} /$ day (Figure 3). In total, $73 \%$ of patients in the $4.8 \mathrm{~g} /$ day group demonstrated improvement in both rectal bleeding and stool frequency by day 14 , compared to $61 \%$ in the $2.4 \mathrm{~g} /$ day group ( $p=0.046$; Figure 3 ). Resolution of 
both rectal bleeding and stool frequency occurred in $43 \%$ of patients receiving $4.8 \mathrm{~g} /$ day, and $30 \%$ of patients receiving $2.4 \mathrm{~g} /$ day $(\mathrm{p}=0.035$; Figure 3$)$.

Overall, $89 \%$ of patients experienced improvement in rectal bleeding by day 14 with $4.8 \mathrm{~g} /$ day, of whom $64 \%$ observed a complete absence of blood in their stool at this time point (Figure 3). Significantly more patients in the $4.8 \mathrm{~g} /$ day group experienced improvement or resolution of rectal bleeding, compared to the 2.4 g/day group (improvement, $p=0.040$; resolution, $p=0.011$; Figure 3 ). № statistically significant differences were observed between doses in the number of patients experiencing improvement or resolution of stool frequency, with more than $80 \%$ of patients in both treatment groups experiencing symptom

improvement (improvement, $\mathrm{p}=0.375$; resolution, $\mathrm{p}=0.329$; Figure 3 ).

Deleted: More patients receiving 4.8 $\mathrm{g} /$ day experienced improvement or resolution of stool frequency, compared to $2.4 \mathrm{~g} /$ day; however, no statistically significant difference was observed

Symptom outcomes after 6 weeks in relation to the 14 day findings

Of the patients in the $4.8 \mathrm{~g} /$ day group who experienced symptom resolution at

week $6,85 \%$ displayed symptom improvement and $65 \%$ displayed symptom resolution at day 14 (rectal bleeding and stool frequency combined). Similar results were observed when each symptom was examined separately; of particular note, $95 \%$ of the patients who experienced resolution of rectal bleeding at week 6 (4.8 g/day group) had experienced improvements by day 14 . In addition, similar findings were observed in the $2.4 \mathrm{~g} /$ day group.

In order to assess the prognostic value of assessments at day 14, patients who experienced symptom improvements at day 14 were examined at the conclusion 
of the study (where data were available). Of the patients in the $4.8 \mathrm{~g} /$ day group who displayed improvement in rectal bleeding after 2 weeks, $86 \%$ also showed improvement in rectal bleeding at week 6 , and $67 \%$ experienced resolution of bleeding (Table 3). Correspondingly, of patients experiencing stool frequency improvement at 2 weeks ( $4.8 \mathrm{~g} /$ day group), $74 \%$ experienced improvements at week 6 , and $52 \%$ showed resolution of this symptom at week 6 (Table 3). Similar findings were observed in the $2.4 \mathrm{~g} /$ day group (Table 3). These findings suggest that the majority of patients who have a clinical improvement at day 14 maintain this improvement at 6 weeks.

To further assess the prognostic value of day 14 , patients who had not responded at day 14 were also considered (Table 4). Of those patients who did not show symptom improvement in rectal bleeding after 14 days, $54 \%$ did not show improvement and 54\% did not show symptom resolution at week 6 (4.8 g/day group; Table 4). Similarly, for stool frequency, of those patients who did not experience improvement at day $14,75 \%$ did not show improvement and $85 \%$ did not show resolution at week 6 ( $4.8 \mathrm{~g} /$ day group; Table 4$)$. Thus, failure to respond at 14 days predicted failure to respond at week 6 in the majority of patients. 


\section{DISCUSSION}

Evaluation of treatment efficacy based on symptom resolution and improvement provides a practical measure of treatment success from the patient's point of view. Symptom resolution is, naturally enough, one of the key goals for UC therapy. ${ }^{1,14}$ However, clinicians are also concerned about under-treatment of active UC and need objective criteria upon which to base decisions to augment therapy, usually with the introduction of steroids. The activity indices that are used in clinical trials, which include endoscopy in addition to symptom scores, may provide a more comprehensive assessment of disease activity; however, it is the assessment of resolution or improvement in symptoms that is of paramount importance to patients. Hence, in daily clinical practice, simple symptom assessments form an integral part of therapeutic decision-making.

The ECCO consensus recommends that if rectal bleeding persists beyond 10-14 days, then response to 5-ASA treatment can be considered slow, and treatment may be augmented if necessary. This often involves the use of oral corticosteroids. ${ }^{11}$ Nearly two-thirds of patients receiving mesalazine $4.8 \mathrm{~g} /$ day achieved resolution of rectal bleeding by day 14 , and almost $90 \%$ demonstrated improvement. This suggests that initial treatment with mesalazine $4.8 \mathrm{~g} / \mathrm{day}$ alone is a valid treatment option for patients experiencing moderately active $U C$, since it provides effective relief of symptoms within 2 weeks. Moreover, $67 \%$ of patients who showed improvement of rectal bleeding after 2 weeks went on to display resolution of rectal bleeding after 6 weeks. Of patients who did not show improvement in rectal bleeding after 2 weeks, only about half went on to 


\section{experience symptom resolution after 6 weeks (irrespective of 5-ASA dose).}

These analyses, combined with the high rate of treatment response at day 14 , confirm that 2 weeks is a clinically relevant period for assessing the response to 5-ASA therapy for patients with moderately active UC, in line with the interval recommended in the ECCO consensus on UC management. ${ }^{11}$ In addition, a recent analysis of the PINCE study has demonstrated that when combining rectal and oral formulations of slow-release mesalazine (Pentasa, Ferring Pharmaceuticals Ltd, Langley, UK), symptom relief can be achieved within 2 weeks for the majority of patients. ${ }^{15}$

This confirmation of the value of the 2-week time point is helpful as it allows clinicians to give patients clear advice about the timescale over which improvement may be expected: it can be explained to patients that improvement of symptoms can be expected within 2 weeks, and if that does not occur then appropriate adjustment of therapy can be made. For example, those patients who still have rectal bleeding after 2 weeks could be asked to telephone to request an early follow-up appointment, or an advice line or telephone follow-up could be offered at 2 weeks to assess progress. This is a more sophisticated approach than making routine follow-up appointments in outpatient clinics. Furthermore, knowledge of the likely timescale of symptoms may help some patients to cope with their symptoms and reduce the impact on their daily lives.

It is generally accepted that corticosteroids, although effective, exert negative side effects and that their use should be avoided if possible. The question is how 
to do this safely, without exposing the patient to a prolonged period of miserable symptoms through under-treatment. The data at day 14 show resolution of rectal bleeding in $64 \%$ of patients, normalization of stool frequency in $58 \%$ of patients, and resolution of both symptoms in $43 \%$ of patients ( $4.8 \mathrm{~g} /$ day group), with improvement of symptoms occurring in even higher percentages. These numbers justify the use of high-dose 5-ASA as first-line treatment in moderately active UC, reserving steroids for those who do not respond.

The data in Figure 3 also allow a comparison between the two mesalazine doses, with regard to the potential need for therapy escalation. If response to treatment were assessed after 14 days, steroids may potentially be used in those patients with persistent rectal bleeding. Thus, in the $2.4 \mathrm{~g} /$ day group, $51 \%$ of patients would receive steroids, compared to $36 \%$ of patients in the $4.8 \mathrm{~g} /$ day group - a potential reduction in steroid use of $29 \%$.

There are some limitations in the current analyses, as with all post hoc analyses. For example, exclusion of patients receiving 5-ASA $>1.6 \mathrm{~g} /$ day from the original $\underline{\text { studies means that it is unclear how applicable the current findings are to patients }}$ receiving higher maintenance doses of 5-ASA before treatment of the active disease. Furthermore, it is not known how well symptom relief correlates with overall clinical remission, or endoscopic mucosal healing. Symptom scores in these analyses were based on patient self-assessments, so are relatively subjective, although it can be argued that the perception of their own symptoms is what matters most to the patient. There is considerable variability in what 
patients consider a 'normal' stool frequency to be, and the definition of normality may change over time for individual patients. ${ }^{5}$ Since the definition of remission in any individual clinical trial may have a considerable effect on the study outcome ${ }^{16}$ variations in patients' definitions of normality would almost certainly affect apparent treatment efficacy. However, it is difficult to see how more objective methods of measuring symptoms might be achieved, and patientassessed symptom relief provides a valuable insight into their perspective of treatment success.

The data presented here suggest that assessment of the response to treatment can be judged at 14 days, since the large majority of those who will respond to mesalazine will have experienced cessation of rectal bleeding or noticeable improvement in their symptoms within this period. By starting mesalazine treatment with a high dose of $4.8 \mathrm{~g} /$ day, symptoms can be relieved rapidly, allowing patients to cope better with the relapse and resume normal daily activities. The comparison of results seen after 2 weeks with the results after 6 weeks provides useful information (albeit limited), which supports making assessment after 2 weeks of treatment a nodal point for therapeutic decision making.

\section{REFERENCES}

(1) Van Assche G, Ghosh S, Panés J, Colombel J, Daperno M, Mitchell R. Insights into patient and physician communication and expectations: results of a large pan-european survey of physicians and their patients with inflammatory bowel disease. J Crohn's Colitis 2008;2(1):47. Abstract P139. 
(2) Collins P, Rhodes J. Ulcerative colitis: diagnosis and management. BMJ 2006;333(7563):340-3.

(3) Ghosh S, Mitchell R. Impact of inflammatory bowel disease on quality of life: Results of the European Federation of Crohn's and Ulcerative Colitis Associations (EFCCA) patient survey. J Crohn's Colitis 2007;1:10-20.

(4) Stange EF, Travis SPL, Vermeire S, Reinisch W, Geboes K, Barakauskiene A, et al. European evidence-based consensus on the management of ulcerative colitis: Definitions and diagnosis. J Crohn's Colitis 2008;2(1):1-23.

(5) Hall NJ, Rubin GP, Dougall A, Hungin AP, Neely J. The fight for 'healthrelated normality': a qualitative study of the experiences of individuals living with established inflammatory bowel disease (IBD). J Health Psychol 2005;10(3):443-55.

(6) Crohn's and Colitis Foundation of America. The Voices of UC survey. 2009 Available from: http://www.livingwithuc.com/livingwithuc/voices/survey findings.html [Last accessed March 2010]

(7) Higgins PD, Schwartz M, Mapili J, Krokos I, Leung J, Zimmermann EM. Patient defined dichotomous end points for remission and clinical improvement in ulcerative colitis. Gut 2005;54(6):782-8.

(8) D'Haens G, Sandborn WJ, Feagan BG, Geboes K, Hanauer SB, Irvine EJ, et al. A review of activity indices and efficacy end points for clinical trials of medical therapy in adults with ulcerative colitis. Gastroenterology 2007;132(2):763-86.

(9) Kornbluth A, Sachar DB. Ulcerative colitis practice guidelines in adults (update): American College of Gastroenterology, Practice Parameters Committee. Am J Gastroenterol 2004;99(7):1371-85.

(10) Carter MJ, Lobo AJ, Travis SP. Guidelines for the management of inflammatory bowel disease in adults. Gut 2004;53(Suppl 5):V1-16.

(11) Travis SPL, Stange EF, Lémann M, Oresland T, Bemelman WA, Chowers $Y$, et al. European evidence-based consensus on the management of ulcerative colitis: Current management. J Crohn's Colitis 2008;2(1):24-62.

(12) Hanauer SB, Sandborn WJ, Dallaire C, Archambault A, Yacyshyn B, Yeh $\mathrm{C}$, et al. Delayed-release oral mesalamine $4.8 \mathrm{~g} /$ day (800 $\mathrm{mg}$ tablets) compared to $2.4 \mathrm{~g} /$ day (400 $\mathrm{mg}$ tablets) for the treatment of mildly to moderately active ulcerative colitis: The ASCEND I trial. Can J Gastroenterol 2007;21(12):827-34. 
(13) Hanauer SB, Sandborn WJ, Kornbluth A, Katz S, Safdi M, Woogen S, et al. Delayed-release oral mesalamine at $4.8 \mathrm{~g} /$ day $(800 \mathrm{mg}$ tablet) for the treatment of moderately active ulcerative colitis: the ASCEND II trial. Am J Gastroenterol 2005;100(11):2478-85.

(14) Gray JR, Leung E, Scales J. Treatment of ulcerative colitis from the patient's perspective: a survey of preferences and satisfaction with therapy. Aliment Pharmacol Ther 2009;29(10):1114-20.

(15) Marteau P, Oudkerk-Pool M, Karlen P, et al. Early response to combined oral and topical mesalazine (Pentasa ${ }^{\circledR}$ ) for ulcerative colitis: post-hoc analysis of efficacy at two weeks in the PINCE trial. ECCO, Feb 2010, Prague Abstract P122. 2010.

(16) Katz S, Kane S, Higgins P, Eusebio R, Yacyshyn B. Different definitions of remission for ulcerative colitis result in large variations of clinical outcome scores. Gastroenterol 2006;130:A482.

\section{ACKNOWLEDGEMENTS}

The authors thank the investigators and patients in the ASCEND I and II studies for participating in these clinical trials, and acknowledge the statistical support of David Ramsey (employee of Procter and Gamble, Ohio) and the assistance of Gwen Wiseman (employee of Warner Chilcott UK Ltd) in the preparation of this paper. Writing and editorial support was provided by Acumen Healthcare Communications Ltd.

\section{STATEMENT OF INTERESTS}

\section{Authors' declaration of personal interests}

1. Dr Timothy Orchard has served as a speaker, a consultant and an advisory board member for Procter \& Gamble Pharmaceuticals (now Warner Chilcott), Ferring Pharmaceuticals and Shire, as well as companies making treatment for ulcerative colitis other than 
1

2

3

4

5

6

7

8

9

10

11

12

13

14

15

16

17

18

19

20

21

22

23

24

25

26

27

28

29

30

31

32

33

34

35

36

37

38

39

40

41

42

43

44

45

46

47

48

49

50

51

52

53

54

55

56

57

58

59

60

aminosalicylate derivatives. He has received research funding from

Procter and Gamble Pharmaceuticals and Johnson and Johnson.

2. Dr Simon Travis has served as a speaker, a consultant or an advisory board member for Procter \& Gamble Pharmaceuticals (now Warner Chilcott), Ferring Pharmaceuticals, Giuliani SpA, UCB Pharma, Shire and Tillotts, as well as companies making treatment for ulcerative colitis other than aminosalicylate derivatives. He has received research funding from Procter \& Gamble Pharmaceuticals (now Warner Chilcott), Ferring Pharmaceuticals, Cosmo Pharmaceuticals and UCB Pharma.

3. Stefan van der Geest is an employee of Warner Chilcott UK Ltd, and was involved in the design of the post hoc analyses.

\section{Declaration of funding interests}

The research and writing of this paper were funded in full by Warner Chilcott UK Ltd. 


\section{TABLES}

Table 1. Symptom scoring scales for rectal bleeding and stool frequency (based

on the ulcerative colitis disease activity index, UC-DAI)

\begin{tabular}{ll}
\hline Stool frequency \\
0 & Normal stool frequency \\
1 & $1-2$ stools per day greater than normal frequency \\
2 & $3-4$ stools per day greater than normal frequency \\
3 & 5 or more stools per day greater than normal frequency \\
\hline Rectal bleeding \\
0 & No visible blood in stool \\
1 & Streaks of blood with stool less than half of the time \\
2 & Obvious blood with stool most of the time \\
3 & Blood alone passed \\
\hline
\end{tabular}


Table 2. Baseline demographics and disease characteristics for all randomized patients with moderately active ulcerative colitis

\begin{tabular}{|c|c|c|}
\hline & $\begin{array}{c}2.4 \text { g/day (N=235) } \\
\text { n (\%) }\end{array}$ & $\begin{array}{c}4.8 \mathrm{~g} / \mathrm{day}(\mathrm{N}=213) \\
\mathrm{n}(\%)\end{array}$ \\
\hline \multicolumn{3}{|l|}{ Number of patients with symptom score data } \\
\hline Rectal bleeding & 174 & 161 \\
\hline Stool frequency & 186 & 160 \\
\hline Rectal bleeding and stool frequency combined & 158 & 133 \\
\hline \multicolumn{3}{|l|}{ Age (years) } \\
\hline Mean & 42.6 & 43.4 \\
\hline \multicolumn{3}{|l|}{ Disease extent } \\
\hline Proctitis & $35(14.9)$ & $32(15.0)$ \\
\hline Left-sided colitis & $147(62.6)$ & $134(62.9)$ \\
\hline Pancolitis & $53(22.6)$ & $47(22.1)$ \\
\hline \multicolumn{3}{|l|}{ Prior treatment } \\
\hline Corticosteroids (oral or intravenous) & $80(34.0)$ & $68(31.9)$ \\
\hline Immunomodulators & $10(4.3)$ & $9(4.2)$ \\
\hline Sulfasalazine & $89(37.9)$ & $65(30.5)$ \\
\hline Sulfa-free oral 5-ASA & $93(39.6)$ & $96(45.1)$ \\
\hline Any oral 5-ASA & $142(60.4)$ & $127(59.6)$ \\
\hline Rectal therapy & $94(40.0)$ & $86(40.4)$ \\
\hline \multicolumn{3}{|l|}{ Baseline stool frequency score } \\
\hline 0 (normal) & $17(7.2)$ & $18(8.5)$ \\
\hline 1 (1-2 greater than normal) & $86(36.6)$ & $60(28.2)$ \\
\hline 2 (3-4 greater than normal) & $80(34.0)$ & $96(45.1)$ \\
\hline 3 ( $\geq 5$ greater than normal) & $52(22.1)$ & $39(18.3)$ \\
\hline \multicolumn{3}{|l|}{ Baseline rectal bleeding score } \\
\hline 0 (none) & $30(12.8)$ & $14(6.6)$ \\
\hline 1 (streaks, $<50 \%$ of time) & $58(24.7)$ & $62(29.1)$ \\
\hline 2 (obvious, most of time) & $126(53.6)$ & $123(57.7)$ \\
\hline 3 (blood alone) & $21(8.9)$ & $14(6.6)$ \\
\hline
\end{tabular}


Table 3. Response after 6 weeks for patients with symptom improvement at day 14 , for patients with moderately active ulcerative colitis

\begin{tabular}{|c|c|c|}
\hline & $\begin{array}{c}2.4 \text { g/day } \\
\text { n (\%) }\end{array}$ & $\begin{array}{c}4.8 \text { g/day } \\
n(\%)\end{array}$ \\
\hline Improvement in stool frequency at day 14 & $131(100)$ & $121(100)$ \\
\hline Improvement in stool frequency at Week 6 & $99(76)$ & $89(74)$ \\
\hline No Improvement in stool frequency at Week 6 & $32(24)$ & $32(26)$ \\
\hline Improvement in stool frequency at day 14 & $131(100)$ & $121(100)$ \\
\hline Resolution of stool frequency at Week 6 & $69(53)$ & $63(52)$ \\
\hline No Resolution of stool frequency at Week 6 & $62(47)$ & $58(48)$ \\
\hline Improvement in rectal bleeding at day 14 & $112(100)$ & $125(100)$ \\
\hline Improvement in rectal bleeding at Week 6 & $94(84)$ & $108(86)$ \\
\hline No Improvement in rectal bleeding at Week 6 & $18(16)$ & $17(14)$ \\
\hline Improvement in rectal bleeding at day 14 & $112(100)$ & $125(100)$ \\
\hline Resolution of rectal bleeding at Week 6 & $69(62)$ & $84(67)$ \\
\hline No Resolution of rectal bleeding at Week 6 & $43(38)$ & 41 (33) \\
\hline \multicolumn{3}{|c|}{ All improvements in symptom score are defined relative to the patient's baseline score. Patient } \\
\hline
\end{tabular}




\section{FIGURE LEGENDS}

Figure 1. Median time to improvement or resolution of rectal bleeding, stool frequency and both symptoms combined, in patients with moderately active ulcerative colitis. (A) Median time to symptom resolution (symptom score $=0$ ); (B) Median time to symptom improvement (symptom score decreased by $\geq 1$ ).

Figure 2. Symptom improvement and resolution over time (rectal bleeding and stool frequency symptoms combined) in patients with moderately active ulcerative colitis.

Figure 3. Percentage of patients with moderately active ulcerative colitis who experienced symptom improvement (symptom score decreased by $\geq 1$ ) or resolution (symptom score $=0$ ) at day 14 . 


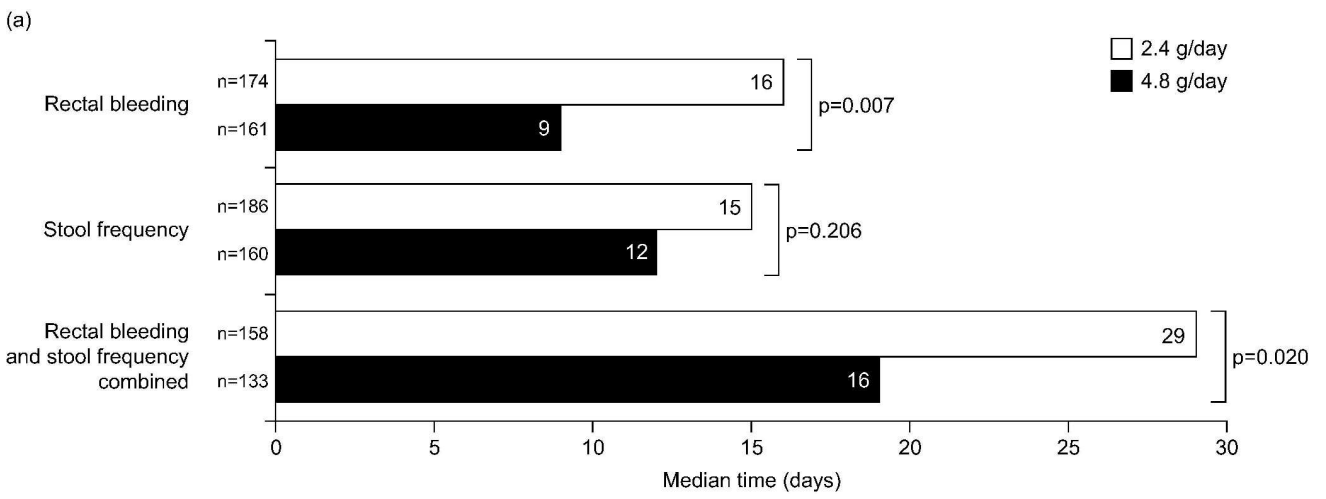

Figure $1 \mathrm{~A}$

$175 \times 65 \mathrm{~mm}(600 \times 600 \mathrm{DPI})$

1

2

3

4

5

6

7

9

10

11

12

13

14
15
16

16

17

18

19

20

21

22

23

27

28

29

30

31

32

33

34

35

36

37

38

39

40

41

42

43

44

45

46

47

48

49

50

51

52

53

54

55

56

57

58

59

60 
(b)

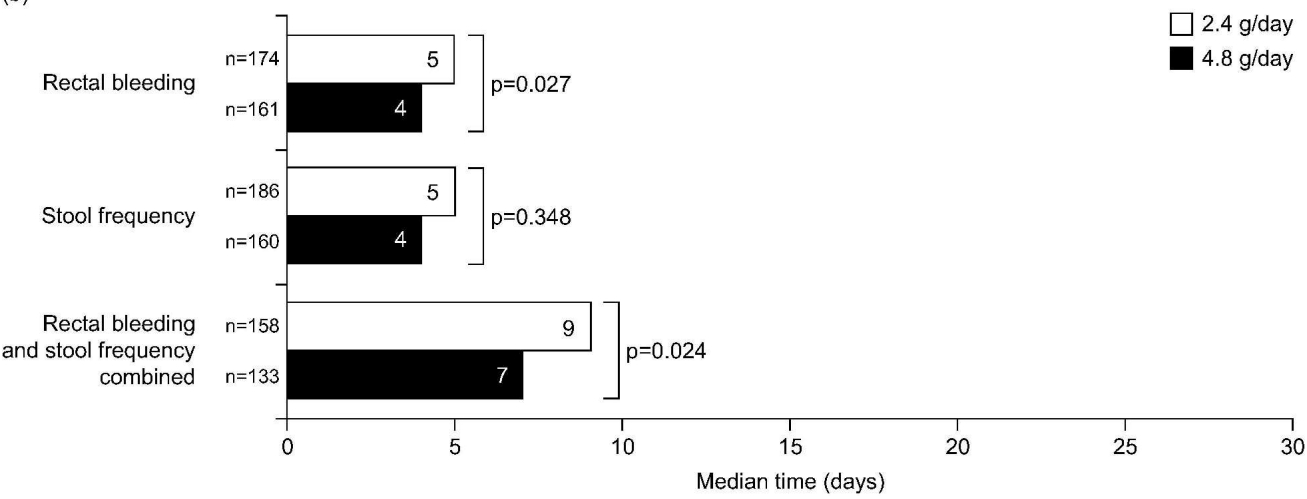

Figure 1B

$165 \times 65 \mathrm{~mm}(600 \times 600$ DPI $)$ 


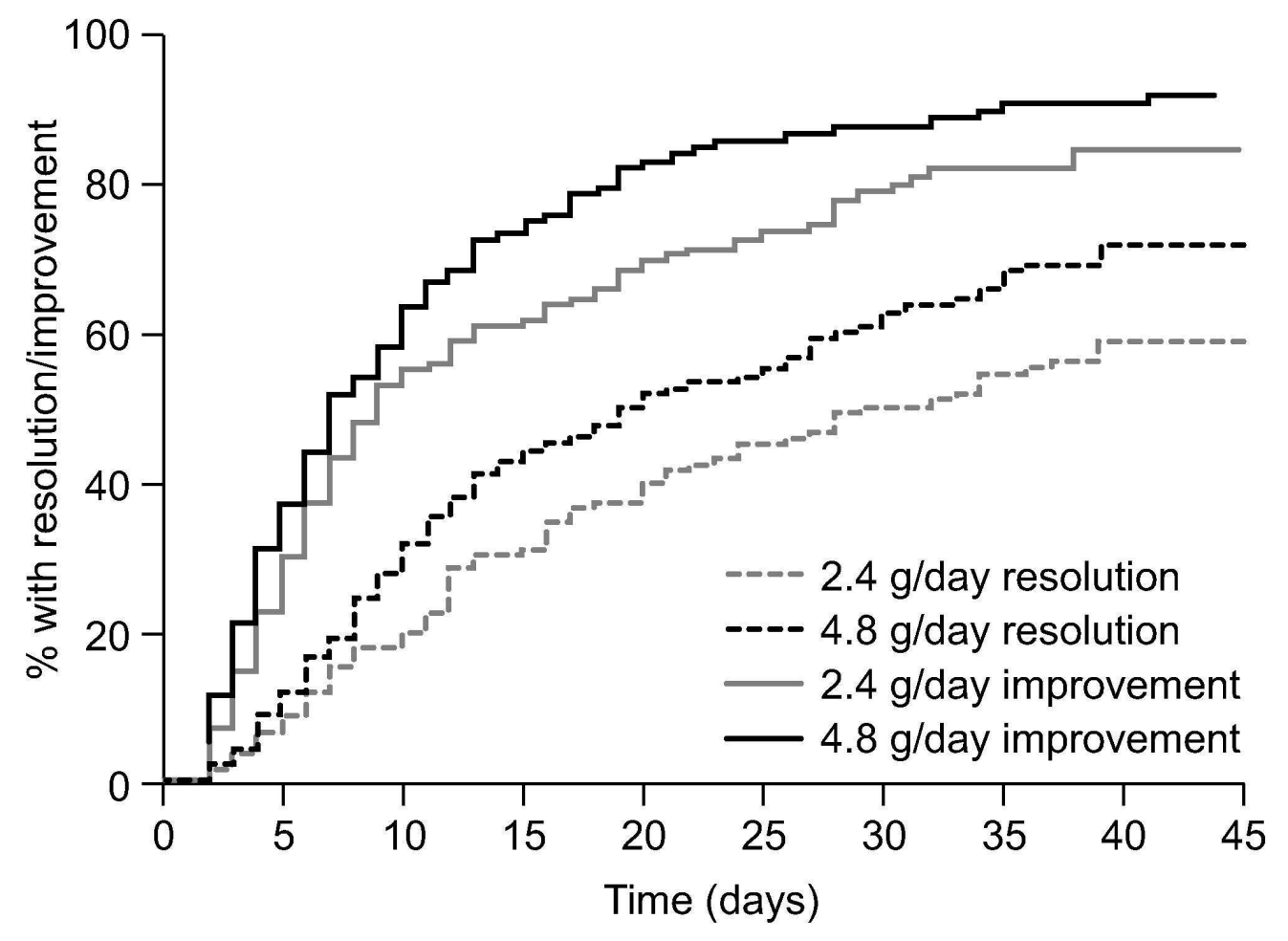

Figure 2

$85 \times 62 \mathrm{~mm}(600 \times 600$ DPI $)$ 
$2.4 \mathrm{~g} /$ day $\quad 4.8 \mathrm{~g} / \mathrm{day}$

${ }^{*} p<0.05$ for both

$\square$ Improvement

Improvement improvement and

$\square$ Resolution

Resolution

resolution

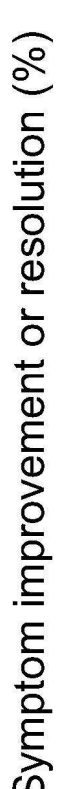

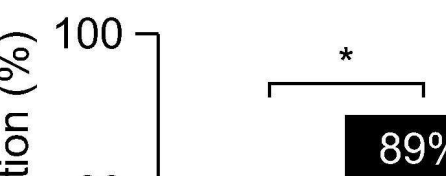

Figure 3 